\title{
ANALYSIS OF PROXIMITY COUPLED EQUILATERAL TRIANGULAR MICROSTRIP ANTENNA
}

\author{
Mahesh C $\mathbf{P}^{1}$, Mallikarjun $S \mathrm{~L}^{2}$, Hadalgi $\mathbf{P} \mathbf{M}^{3}$, Hunagund $\mathbf{P} \mathbf{V}^{4}$ \\ ${ }^{1}$ Research Student, Dept. of Applied Electronics, Gulbarga University, Gulbarga, Karnataka, India \\ ${ }^{2}$ Guest Faculty, Dept. of Applied Electronics, Gulbarga University, Gulbarga, Karnataka, India \\ ${ }^{3}$ Professor, Dept of Applied Electronics, Gulbarga University, Gulbarga, Karnataka, India \\ ${ }^{4}$ Professor, Dept of Applied Electronics, Gulbarga University, Gulbarga, Karnataka, India
}

\begin{abstract}
A proximity-coupled Equilateral Triangular microstrip antenna (PCETMSA) is proposed. The proximity-coupled antenna is simpler in design with low fabrication cost. The bandwidth and gain of the antenna can be increased by increasing the substrate thickness by retaining the same radiation pattern. The antenna consists of two substrates made up of glass epoxy material with the same thickness (h). The antenna is analyzed by increasing the thickness from $0.16 \mathrm{~cm}$ to 0.32 and further the thickness of the antenna is increased to $0.64 \mathrm{~cm}$. The experimentally measured and calculated antenna parameters such as return loss, VSWR, radiation pattern, gain and $H P B W$ are presented. The design considerations are also presented.
\end{abstract}

Keywords: Microstrip patch antenna, Proximity coupled, Substrate thickness, HPBW, Gain and VSWR.

\section{INTRODUCTION}

In today's modern communication industry, antennas are the most important components required to create a communication link. Through the years, microstrip patch antenna structures are the most common option used to realize with monolithic integrated circuits for microwave, radar and communication purposes. The shape and operating mode of the patch are selected, designs become very versatile in terms of operating frequency, polarization, pattern and impedance. [1]

A configuration of non-contacting non-coplanar microstrip line fed antenna uses a two layer substrate with the microstrip line on the lower layer and the patch antenna on the upper layer. The feed-line terminates underneath the patch. This feed is better known as an "electromagnetically coupled" microstrip feed. Coupling between the patch and microstrip is capacitive in nature. [2]

\section{ANTENNA DESIGN}

The proposed antenna in this study is designed for the frequency of $3 \mathrm{GHz}$ using the relations present in the literature for the design of equilateral triangular microstrip antenna.[1] A low cost glass epoxy substrate material of same thickness and dielectric constant $\varepsilon_{\mathrm{r}}=4.2$ is used to fabricate the antenna.[3]

The geometry of proximity-coupled equilateral triangular microstrip antenna (PCETMSA) is shown in Fig. 1. An equilateral triangular radiating patch with length ' $\mathrm{a}$ ' is etched on top surface of substrate $S_{1}$.[4] The value of ' $a$ ' is obtained from the equation;

$$
a=\frac{2 C}{3 f_{r} \sqrt{\varepsilon_{r}}}
$$

Where $\mathrm{C}$ is the velocity of light and $\mathrm{f}_{\mathrm{r}}$ is the resonating frequency. The microstripline feed of length $\mathrm{L}_{\mathrm{f}}$ and width $\mathrm{W}_{\mathrm{f}}$ is etched on the top surface of substrate $S_{2}$. The substrate $S_{2}$ is placed below substrate $S_{1}$ such that the tip of the feedline and the center of the radiating patch coincide one over the other. The bottom surface of the substrate $S_{2}$ acts as the ground plane. The $h$ and $\varepsilon_{\mathrm{r}}$ of substrates $\mathrm{S}_{1}$ and $\mathrm{S}_{2}$ are same. The proposed antenna is sketched using the computer software AUTOCAD to achieve better accuracy. The antenna is fabricated using the photolithography process.

Further, the study is made by increasing the thickness (h) of both the substrate $S_{1}$ and $S_{2}$. 


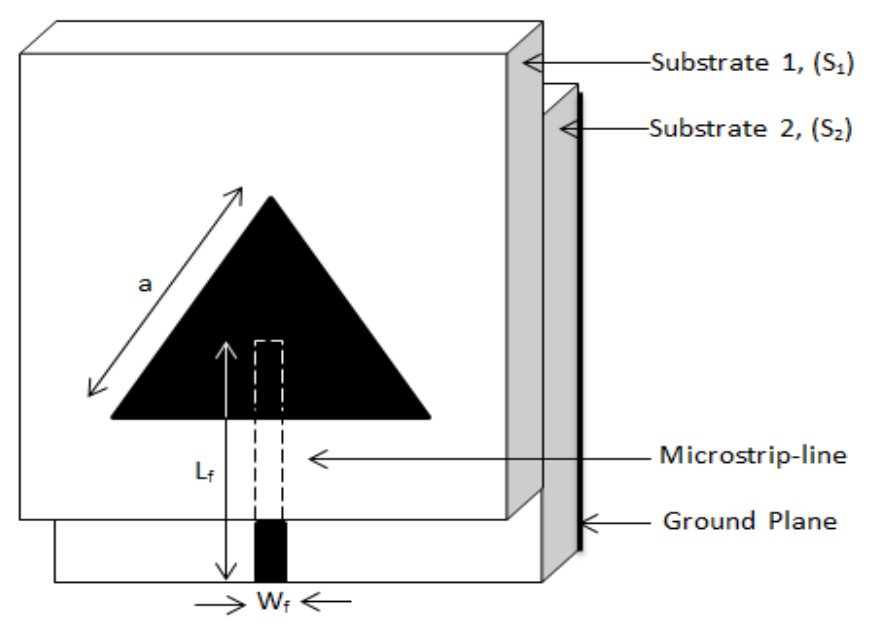

Fig-1: Geometry of PCETMSA

\section{EXPERIMENTAL RESULTS AND DISCUSSION}

The impedance bandwidths over return loss less than $-10 \mathrm{~dB}$ for the proposed antennas are measured. The measurements are taken on Vector Network Analyzer (Rohde \& Schwarz, German make ZVK Model No. 1127.8651). The variation of return loss versus frequency of PCETMSA with different thickness is shown in Fig. 2

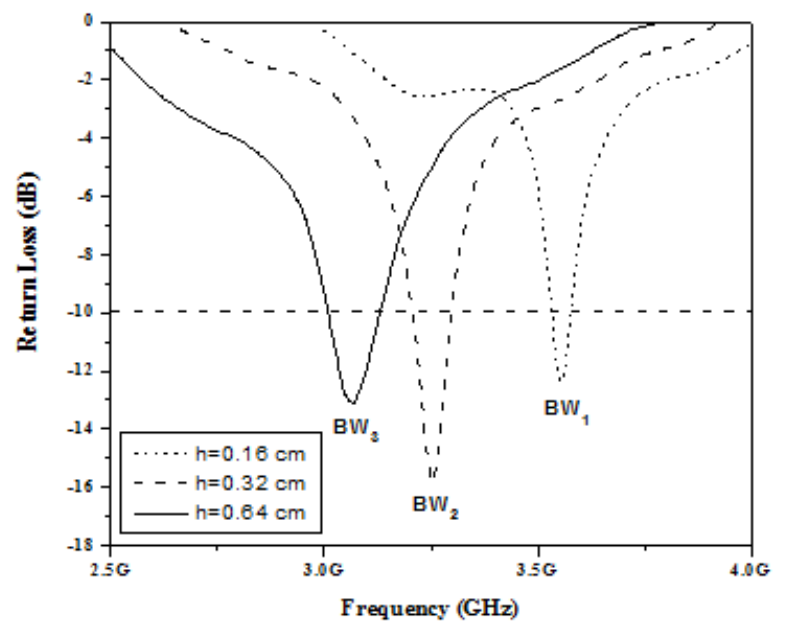

Fig-2: Variation of return loss v/s frequency of PCETMSA with different thickness (h)

From the graph it is observed that, PCETMSA with thickness, $\mathrm{h}=0.16 \mathrm{~cm}, 0.32 \mathrm{~cm}$ and $0.64 \mathrm{~cm}$ resonates at $3.55 \mathrm{GHz}, 3.25$ $\mathrm{GHz}$ and $3.06 \mathrm{GHz}$ respectively. The experimental impedance bandwidths $\left(\mathrm{BW}_{1}\right)$ is found to be $40 \mathrm{MHz}(1.12 \%),\left(\mathrm{BW}_{2}\right)$ is $80 \mathrm{MHz}(2.4 \%)$, which is 2.14 times more when compared to the antenna with thickness, $\mathrm{h}=0.16 \mathrm{~cm}$. The minimum return loss measured is presented in Table 1. From the table it is clear that the return loss of antenna is also improved by increasing the thickness.
Further, from the graph, the impedance bandwidth $\left(\mathrm{BW}_{3}\right)$ is found to be $110 \mathrm{MHz}$ (3.59\%) which is 3.20 times and 1.49 times more compared to $\left(\mathrm{BW}_{1}\right)$ and $\left(\mathrm{BW}_{2}\right)$ respectively. The minimum return loss measured and VSWR for different thickness (h) is also tabulated in Table 1. The measured VSWR is also presented in Table 1.

Table-1: Measured Min. Return Loss and VSWR

\begin{tabular}{|c|c|c|c|}
\hline $\begin{array}{c}\text { Thickness (h) } \\
\text { in cms. }\end{array}$ & $\begin{array}{c}\text { Freq. in } \\
\text { GHz. }\end{array}$ & $\begin{array}{c}\text { Min. Return } \\
\text { loss in dB. }\end{array}$ & VSWR \\
\hline 0.16 & 3.55 & -12.36 & 1.61 \\
\hline 0.32 & 3.25 & -15.82 & 1.44 \\
\hline 0.64 & 3.06 & -13.07 & 1.59 \\
\hline
\end{tabular}

The X-Y plane co-polar and cross-polar radiation patterns are measured at their resonating frequencies and are shown in Fig. 3 to Fig.5. These figures indicate that the antennas show broader side radiation characteristics. The cross-polarization levels of these antennas are found to be minimum and are tabulated in Table 2. Further the calculated HPBW is also shown in Table 2.

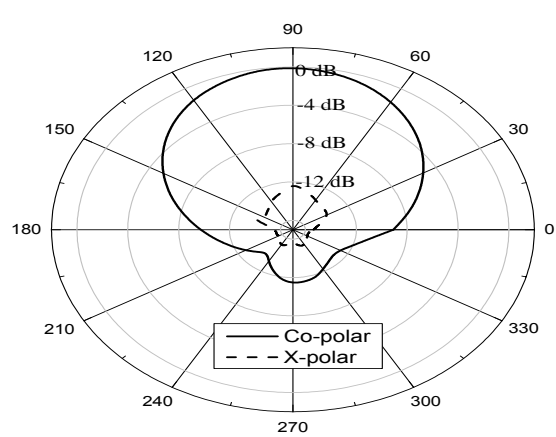

Fig-3: Radiation pattern at $3.55 \mathrm{GHz}$

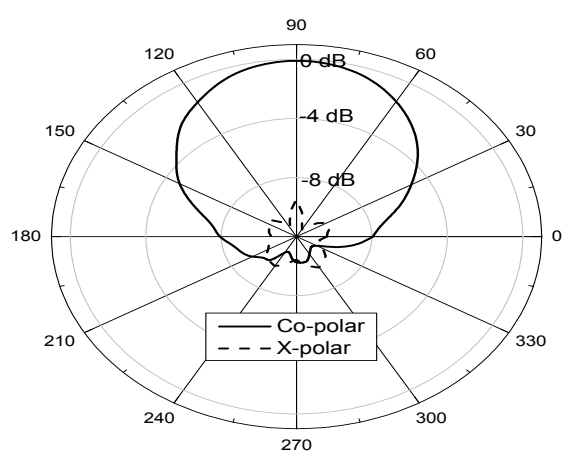

Fig-4: Radiation pattern at $3.25 \mathrm{GHz}$ 


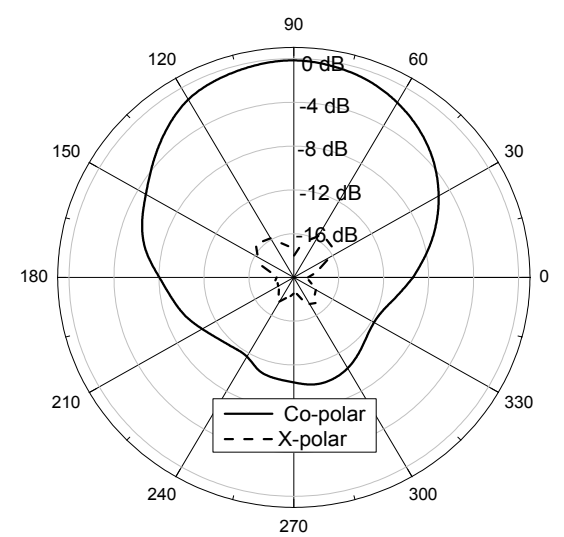

Fig-5: Radiation pattern at $3.06 \mathrm{GHz}$

The gain of proposed antenna is calculated using absolute gain method given by the equation, [5]

$$
G(d B)=10 \log \left(\frac{P_{r}}{P_{t}}\right)-(G t) d B-20 \log \left(\frac{\lambda_{0}}{4 \pi R}\right) d B
$$

Where, $\mathrm{Pt}$ and $\mathrm{Pr}$ are transmitted and received powers respectively, $G t$ is the gain of the pyramidal horn antenna and $\mathrm{R}$ is the distance between transmitting antenna and antenna under test. The gain of the antenna is tabulated in Table 2.

Table-2: Calculated Min. Cross Polarization level, Gain and HPBW

\begin{tabular}{|c|c|c|c|c|}
\hline $\begin{array}{c}\text { Thickness } \\
\text { (h) in cms. }\end{array}$ & $\begin{array}{c}\text { Freq. in } \\
\text { GHz. }\end{array}$ & $\begin{array}{c}\text { Min. Cross } \\
\text { Polar in dB. }\end{array}$ & $\begin{array}{c}\text { Gain } \\
\text { in } \\
\text { dB. }\end{array}$ & $\begin{array}{c}\text { HPBW } \\
\text { in } \\
\text { degrees }\end{array}$ \\
\hline 0.16 & 3.55 & -11.00 & 7.66 & $81^{0}$ \\
\hline 0.32 & 3.25 & -06.00 & 3.06 & $91^{0}$ \\
\hline 0.64 & 3.06 & -16.00 & 11.79 & $87^{0}$ \\
\hline
\end{tabular}

\section{CONCLUSIONS}

The detailed experimental study shows that the antenna is quite simple in design and fabrication and quite good in enhancing the impedance bandwidth and give better gain with broadside radiation pattern at the resonating frequency. The antenna is also superior as it uses low cost substrate material and finds applications in modern communication systems such as WLAN, Wi-Fi and in radar communication systems.

\section{ACKNOWLEDGEMENTS}

The authors express their thanks to the Department of Science and Technology (DST), Govt. of India, New Delhi, for sanctioning Vector Network Analyzer under the FIST
Programme to the Department of Applied Electronics, Gulbarga University, Gulbarga.

\section{REFERENCES}

[1]. I. J. Bahl and P. Bhartia, Microstrip Antennas, Artech House, Dedham, MA, 1980.

[2]. Ramesh Garg, Microstrip antenna design handbook, Artech House, Noorwood, MA, 2001.

[3]. D. M. Pozar and B. Kaufman, "Increasing the Bandwidth of a Microstrip Antenna by Proximity Coupling”, Microstrip Antennas, John Wiley and sons, Inc., New Jersey, vol. 23, no. 8, pp368-369, April 1987.

[4]. Indra surjati, K. N. Yuli and Yuliastati, "Increasing bandwidth dual frequency triangular microstrip antenna for Wi-Max application" International Journal of Electrical \& Computer Sciences, vol. 10, no. 6, December 2010.

[5]. C. A. Balanis, Antenna Theory Analysis and Design, John Wiley and Sons, New York, 1982. 